\title{
Long-term outcomes of transoral incisionless fundoplication for gastro-esophageal reflux disease: systematic-review and meta-analysis
}

두(1) $(9$

\begin{abstract}
Authors
Institutions

1 Division of Pancreatico-Biliary Endoscopy \& Endosonography, Vita-Salute San Raffaele University, Scientific Institute San Raffaele, Milan, Italy

2 Ospedale Nuovo Regina Margherita, Digestive Endoscopy Unit, Rome, Italy

3 Ospedale di Treviglio - Caravaggio, ASST Bergamo Ovest, Digestive Endoscopy Unit, Bergamo, Italy

4 Division of Gastroenterology \& Gastrointestinal Endoscopy, Vita-Salute San Raffaele University, San Raffaele Scientific Institute, Milan, Italy

5 Im3D Clinic Piemonte S.c.a.r.l., Medical Imaging Lab, Torino, Italy
\end{abstract}

Sabrina Testoni ${ }^{*}, 1$, Cesare Hassan ${ }^{*}, 2$, Giorgia Mazzoleni ${ }^{3}$, Giulio Antonelli ${ }^{2}$, Lorella Fanti ${ }^{4}$, Sandro Passaretti ${ }^{4}$, Loredana Correale ${ }^{5}$, Giulia Martina Cavestro ${ }^{4}$, Pier Alberto Testoni ${ }^{4}$

submitted 15.7.2020

accepted after revision $\quad 20.10 .2020$

Bibliography

Endoscopy International Open 2021; 09: E239-E246

DOI 10.1055/a-1322-2209

ISSN 2364-3722

(c) 2021. The Author(s).

This is an open access article published by Thieme under the terms of the Creative Commons Attribution-NonDerivative-NonCommercial License, permitting copying and reproduction so long as the original work is given appropriate credit. Contents may not be used for commecial purposes, or adapted, remixed, transformed or built upon. (https://creativecommons.org/licenses/by-nc-nd/4.0/)

Georg Thieme Verlag KG, Rüdigerstraße 14,

70469 Stuttgart, Germany

Corresponding author

Pier Alberto Testoni, MD, Division of Gastroenterology \& Gastrointestinal Endoscopy, Vita-Salute San Raffaele University, San Raffaele Scientific Institute, Via Olgettina 58, 20132 Milan, Italy

Fax: +39-2-26433491

testoni.pieralberto@hsr.it
丹 Supplementary material is available under https://doi.org/10.1055/a-1322-2209

\section{ABSTRACT}

Background and study aims Few reports exist about long-term outcomes of transoral incisionless fundoplication (TIF) for treating refractory gastro-esophageal reflux disease (GERD).

Methods A literature search of four major scientific databases was performed up to May 2020 for studies reporting on more than 3-year outcomes of TIF. Data on atient satisfaction, proton pump inhibitor (PPI) daily consumption, PPI use reduction, GERD health-related quality-of-life (GERDHRQL) score, and normalization of heartburn and regurgitation scores were pooled and summarized with forest plots. Publication bias and heterogeneity were explored.

Results Overall, eight studies (418 patients, 232 men; $55.5 \%$ ) with a mean follow-up of 5.3 years (range: $3-10$ years) were included. The pooled proportion of patient-reported satisfaction before and after TIF was 12.3\% (95\% $\left.\mathrm{Cl}: 12.3-35.1 \%, \mathrm{I}^{2}=87.4 \%\right)$ and $70.6 \%(95 \% \mathrm{Cl}: 51.2-84.6$, $\left.\mathrm{I}^{2}=80 \%\right)$, respectively, corresponding to an odds ratio of 21.4 (95\% Cl:3.27-140.5). Pooled rates of patients completely off PPIs and on occasional PPIs were $53.8 \%(95 \% \mathrm{Cl}$ : $42.0 \%-65.1 \%$ ) and $75.8 \%$ (95\%Cl: 67.6-82.6), respectively. The pooled estimated mean GERD-HRQL scores off PPI before and after TIF werey 26.1 (95\% Cl: 21.5-30.7; range: 20.0-35.5) and 5.9, respectively (95\% Cl:0.35.1-11.4; range: 5.3-9.8; $P<0.001)$. The overall pooled rates of heartburn and regurgitation scores normalization were $73.0 \%(95 \% \mathrm{Cl}: 0.62-0.82)$ and $86 \%$, respectively $(95 \% \mathrm{Cl}$ : 75.0-91.0\%).

Conclusion Our study shows that TIF appears to offer a long-term safe therapeutic option for selected patients with GERD who refuse life-long medical therapy or surgery, are intolerant to PPIs, or are at increased surgical risk.

* These authors contributed equally. 


\section{Introduction}

Transoral incisionless fundoplication (TIF) currently is used to restore the continence of the gastroesophageal junction in selected patients suffering from gastroesophageal reflux disease (GERD), with either a competent gastroesophageal valve or hiatal hernia $<2.5 \mathrm{~cm}$, who refuse or are intolerant or unresponsive to proton pump inhibitor (PPI) maintenance therapy.

TIF reconfigures the tissue to establish a full-thickness gastroesophageal valve from inside the stomach and has been performed by using either the EsophyX device (EndoGastric Solutions, Redmond, Washington, United States) or Medigus ultrasonic surgical endostapler (MUSE, Medigus, Omer, Israel). The technique mimicks a $180^{\circ}$ up to $270^{\circ}$ surgical fundoplication, depending upon the device used, but is less invasive and is not associated with persistent surgery-related side effects.

Several studies have shown the efficacy of TIF in obtaining a significant improvement in both typical and atypical GERDrelated symptoms, and reduction in the acid exposure time with 2-year follow-up [1, 2]; however, few studies have assessed long-term outcomes of TIF, raising concerns about the longterm performance of the procedure, compared with surgical outcomes [3].

The aim of this meta-analysis was to assess long-term outcomes of TIF in terms of patient satisfaction, quality of life, and use of PPIs.

\section{Methods}

\section{Registration}

This review was registered on the PROSPERO international database (from University of York Centre for Reviews and dissemination) (registration ID 169382).

\section{Search strategy and study selection}

A computerized search of PubMed, Scopus, Embase/Medline, and Cochrane Library databases was executed to identify publications from inception to May 2020 that included patients treated with endoscopic TIF procedures, with either EsophyX $1.0 / 2.0$ or the MUSE technique. The following search terms were used: transoral incisionless fundoplication, transoral fundoplication, TIF, EsophyX, MUSE, Medigus, endoscopic treatment of gastroesophageal reflux/GERD, gastroesophageal reflux. Titles of all the identified articles were screened to exclude studies not related to study topic or meeting one of the exclusion criteria. The remaining potentially relevant studies were screened for eligibility by analysis of the abstract and the full text. Studies reporting data on TIF fundoplication with long term outcomes ( $\geq 3$ years) were included in the quantitative synthesis through meta-analysis (see below for inclusion criteria). An analysis of references for each included article was made to retrieve additional eligible studies. The methodology was developed from the Preferred Reporting Items for Systematic Reviews and Meta-Analyses (PRISMA) checklist [4].

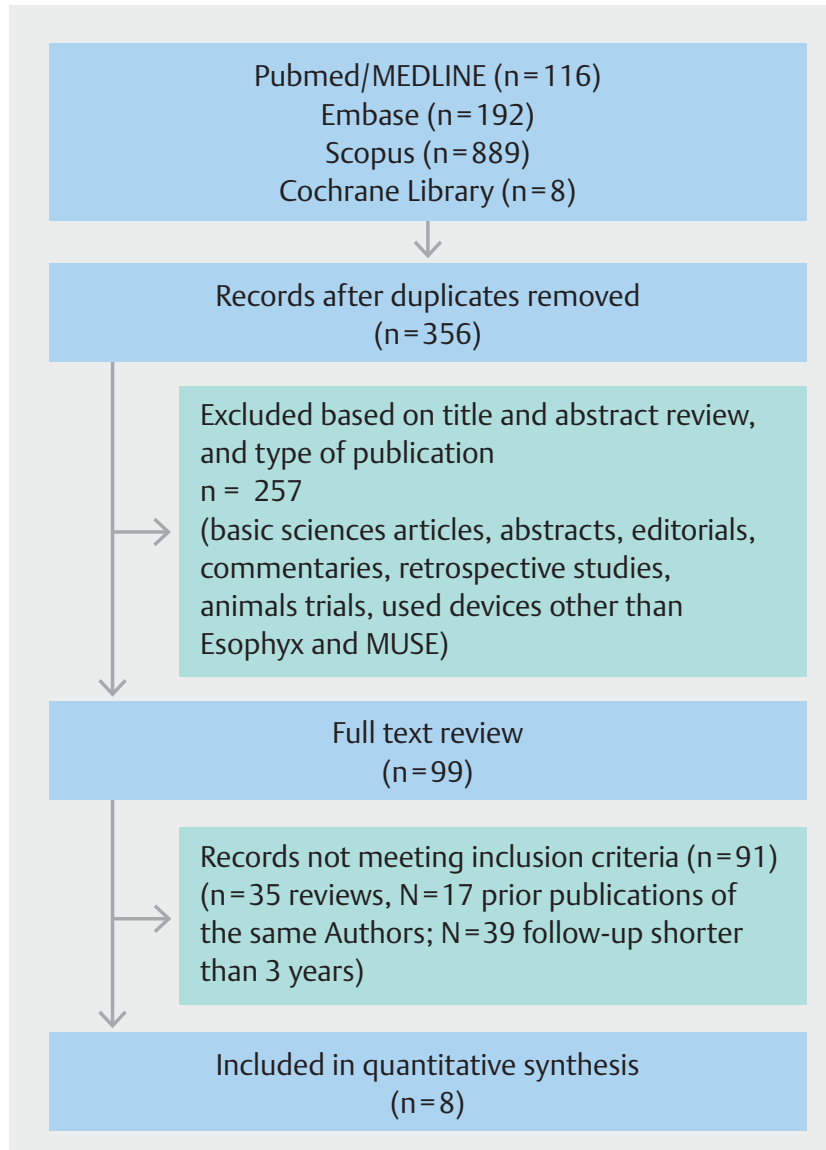

- Fig. 1 Excluded studies and reasons for their exclusion.

\section{Inclusion and exclusion criteria}

The analysis included all studies published in English reporting long-term outcomes of patients undergoing TIF fundoplication with either MUSE or EsophyX. We adopted as cut-off between short- and long-term outcomes a period of 3 years. Thus, all studies reporting only short-term ( $<3$ years) outcomes were excluded. Excluded from the analysis were also all studies published in languages other than English, as well as conference abstracts, book chapters, reviews, and commentaries, retrospective and unpublished studies. In case of patient overlap between studies, the largest or most recent study was included. Excluded studies and reasons for exclusion were recorded ( Fig. 1).

\section{Data extraction}

Two reviewers (S.T. and G.M.) independently performed the electronic search, comparing results for congruence, in consultation with other investigators when the evaluators' opinions differed. Data extraction was performed independently by the two reviewers and crosschecked by the investigators. From each included study, the following data were extracted: study design, sample size, patient characteristics, duration of followup, TIF technique, device for TIF (EsophyX or MUSE), patient inclusion and exclusion criteria, subjective outcomes (symptomatic relief after TIF), severe adverse events (AEs), and publica- 
tion year. No restrictions with respect to patient age, ethnic group, or sex were adopted. The overall quality of the included studies was judged on the basis of the IHE (Institute of Health Economics) quality appraisal tool for case series studies [5]. The quality assessment checklist includes seven domains with a total of 18 item as follows: study objective ( 1 item), study population ( 5 items), interventions and co-interventions ( 2 items), outcomes measures (3 items), statistical analysis (1 item), results and conclusions (5 items), competing interests and sources of support ( 1 item). Studies complying with 14 or more items (C70\%) were considered to be of acceptable quality. The overall quality of the randomized clinical trials as determined by Jadad et al. [6] was judged.

\section{Statistical analysis}

Outcomes of the meta-analysis were: overall patient satisfaction, PPI daily consumption (stopped or at least halved), mean GERD-health related quality of life (GERD-HRQL) score, normalization of heartburn score, normalization of regurgitation score, before and after TIF. PPI consumption was considered "continued" when the daily drug dose was the same as before the procedure; "reduced" when any daily dose was taken for less than half the total number of days during follow-up; and "completely stopped" when not one dose of PPI was taken during the follow-up. Heartburn and regurgitation scores were extrapolated from the GERD-HRQL questionnaire and assessed separately.

Continuous data were reported as the median (interquartile range $[I Q R]$ ) or mean (standard deviation [SD]), whereas categorical data were reported as the count and percentage. Event rates for binary outcomes (e. g., \% of patients off-PPI) were defined as the proportion of events among the number of patients who were available for follow-up. Standard errors (SEs) and $95 \%$ confidence intervals (Cls) for a single proportion were derived. Heterogeneity among studies was assessed by using the $\mathrm{I}^{2}$ statistic, which describes the percentage of total variation attributable to between-study heterogeneity as opposed to random error or chance. Percentages of $25 \%\left(I^{2}=25\right)$, $50 \%\left(I^{2}=50\right)$, and $75 \%\left(I^{2}=75\right)$ were considered as low, moderate, and high degree of heterogeneity, respectively. In the presence of substantial heterogeneity $\left(I^{2}>50 \%\right)$, a random effects model was used as the pooling method; otherwise, a fixed effects model was adopted as the pooling method. Prediction intervals for size effects of a new study were also calculated according to Higgins et al. [7]. Sensitivity analysis was performed by sequentially omitting each study to test the influence of each individual study on pooled data [8]. The Egger's test and the trim and fill method of Duval and Tweedie were used to test and adjust for publication bias [9]. All statistical analyses were conducted in $\mathrm{R}$. In particular, we used the metafor libraries in $\mathrm{R}$ to carry out the meta-analysis and meta-regression [10].

\section{Results}

\section{Study description}

The PRISMA flowchart and reasons for exclusion are shown in - Fig. 1. The initial electronic search retrieved 356 references. Of the 99 studies screened for eligibility, eight (418 enrolled patients; males: $55.5 \%$ ) were included in the meta-analysis [11-18]. One study was an open label, crossover, multicenter, randomized controlled trial [15]; three were multicenter, prospective studies $[11,13,14]$; and four were single-center, prospective studies $[12,16,17,18]$. Mean follow-up time was 5.3 years (range: $3-10$ years). In detail, two studies had a follow up of 3 years (73 patients) [11,12], four studies up to 4 to 5 years (137 patients) [13-16], and two studies up to 8 to 10 years (35 patients) $[17,18]$. Follow-up of patients was carried out annually in six studies, at 1 and 8 years after TIF in one study [18], and at 1, 2, 3, 5, 7, and 10 years in another study [17].

\section{Patient characteristics}

Median/mean age, body mass index, GERD duration were 44.6 (range 19-79, 4 studies) and $47.1 \pm 13.2$ (3 studies), $25.9 \mathrm{~kg} / \mathrm{m}^{2}$ (range $17.1-36.0$ ) and $25.9 \mathrm{~kg} / \mathrm{m}^{2} \pm 4.1$, and 4.8 years (range $0.5-25$ years) and $11.2 \pm 9.8$ years, respectively. In addition, GERD duration was reported as longer than 3 and 6 months in two studies $[14,17]$, while it was not reported in the remaining study [18]. Daily PPI dependence was $100 \%$ in five studies [1418 ] and $97 \%$ in one study [12], while it was not provided in two studies. The presence of hiatal hernia and esophagitis was reported in six of eight studies [11,12,15-18], and it was $65.8 \%$ and $49.9 \%$, respectively. Studies and patient characteristics for each study are reported in $>$ Table 1.

\section{Procedure details}

EsophyX and MUSE were used in six studies (196 patients) [11, $12,15-18]$ and two studies (49 patients) $[13,14]$, respectively. Among studies using EsophyX, two reported outcomes with TIF $1.0[11,12]$ and four with the TIF 2.0 technique [15-18]. TIF was technically feasible in 414 of 418 patients (99.0\%). Severe AEs occurred in seven of 418 procedures (1.7\%). Pneumothorax was reported in three patients after Esophyx and was the commonest complication of this intervention; pneumomediastinum was reported in one patient after MUSE; 24-hour delayed bleeding occurred in two cases with Esophyx; esophageal mucosal lesion without full-thickness perforation occurred in one case with the introduction of Esophyx. All these AEs resolved spontaneously within 48 hours.

Procedures and follow-up details for each study are reported in $>$ Table 2.

\section{Patient satisfaction at baseline and after TIF}

Before and after TIF, the pooled rate (random-effect) of patient satisfaction was $12.3 \%$ (95\% Cl:12.3-35.1\%, $\mathrm{I}^{2}=87.4 \%$ ) and $70.6 \%$ (95\% Cl:51.2-84.6, $\mathrm{I}^{2}=80 \%$ ), respectively (6 studies, 197 patients) $[11-13,15,16,18]$, with no publication bias (Egger test: $z=-0.1578, P=0.8746)$, corresponding to an odds ratio of 21.4 (95\% Cl:3.27-140.5) ( $>$ Fig. 2). At sensitivity analysis, heterogeneity improved after the exclusion of one study 
- Table 1 Studies and patient characteristics.

\begin{tabular}{|c|c|c|c|c|c|c|c|c|}
\hline $\begin{array}{l}\text { Author, publi- } \\
\text { cation year }\end{array}$ & $\begin{array}{l}\text { Study } \\
\text { design }\end{array}$ & $\begin{array}{l}\text { No.pa- } \\
\text { tients }\end{array}$ & Age, $y r^{1}$ & $\begin{array}{l}\text { BMI, } \\
\mathrm{kg} / \mathrm{m}^{21}\end{array}$ & $\begin{array}{l}\text { Duration of } \\
\text { symptoms }(y r)^{1}\end{array}$ & $\begin{array}{l}\text { Hiatal } \\
\text { hernia \% }\end{array}$ & $\begin{array}{l}\text { Esopha- } \\
\text { gitis \% }\end{array}$ & $\begin{array}{l}\text { PPI consumption } \\
\text { prior to TIF \% }\end{array}$ \\
\hline $\begin{array}{l}\text { Witteman, } \\
2012 \text { [12] }\end{array}$ & $\begin{array}{l}\text { Retro- } \\
\text { spective }\end{array}$ & 38 & $\begin{array}{l}46 \\
(22-79)\end{array}$ & $\begin{array}{l}26.3 \\
(20.1-36.0)\end{array}$ & $6(1-25)$ & 94.8 & 58.0 & 97 \\
\hline Muls, 2013 [11] & $\begin{array}{l}\text { Prospec- } \\
\text { tive }\end{array}$ & 86 & $\begin{array}{l}49 \\
(19-73)\end{array}$ & $\begin{array}{l}25.1 \\
(17.1-35.3)\end{array}$ & $6(1-16)$ & 58.0 & 82.0 & NR \\
\hline $\begin{array}{l}\text { Roy-Shapira, } \\
2015 \text { [13] }\end{array}$ & $\begin{array}{l}\text { Prospec- } \\
\text { tive }\end{array}$ & 15 & $\begin{array}{l}46 \\
(26-64)\end{array}$ & $18-31$ & $2.5(0.5-20)$ & NR & NR & NR \\
\hline $\begin{array}{l}\text { Kim H], } 2016 \\
{[14]}\end{array}$ & $\begin{array}{l}\text { Prospec- } \\
\text { tive }\end{array}$ & 64 & $44.7 \pm 3.3$ & $26.2 \pm 4.9$ & $>6$ months & NR & NR & 100 \\
\hline $\begin{array}{l}\text { Stefanidis, } \\
2017 \text { [16] }\end{array}$ & $\begin{array}{l}\text { Retro- } \\
\text { spective }\end{array}$ & 45 & $\begin{array}{l}36 \\
(23-55)\end{array}$ & $\begin{array}{l}26.2 \\
(18.3-34.9)\end{array}$ & $5(1-24)$ & 71.1 & 73.3 & NR \\
\hline $\begin{array}{l}\text { Trad KS, } 2018 \\
\text { [15] }\end{array}$ & $\begin{array}{l}\text { Prospec- } \\
\text { tive }\end{array}$ & 63 & $51.5 \pm 10.3$ & $28.5 \pm 3.7$ & $11.2 \pm 9.8$ & 87.3 & 52.4 & 100 \\
\hline $\begin{array}{l}\text { Chimukangara } \\
\text { M, } 2019 \text { [18] }\end{array}$ & $\begin{array}{l}\text { Prospec- } \\
\text { tive }\end{array}$ & 57 & $\begin{array}{l}46 \\
(37-59)\end{array}$ & $28.8 \pm 4.9$ & NR & 45.6 & 21.1 & 100 \\
\hline $\begin{array}{l}\text { Testoni PA, } \\
2019 \text { [17] }\end{array}$ & $\begin{array}{l}\text { Prospec- } \\
\text { tive }\end{array}$ & 50 & $45 \pm 16$ & $22 \pm 3$ & $>3$ months & 56.0 & 22.0 & 100 \\
\hline
\end{tabular}

Table 2 Procedures and follow-up details.

\begin{tabular}{|c|c|c|c|c|c|c|c|c|}
\hline $\begin{array}{l}\text { Author, } \\
\text { publication } \\
\text { year }\end{array}$ & $\begin{array}{l}\text { Proce- } \\
\text { dure } \\
\text { device }\end{array}$ & $\begin{array}{l}\text { Techni- } \\
\text { cal suc- } \\
\text { cess \% }\end{array}$ & $\begin{array}{l}\text { Procedure } \\
\text { time (min- } \\
\text { ute) })^{1}\end{array}$ & $\begin{array}{l}\text { Major ad- } \\
\text { verse events, } \\
\text { No. }(\%)\end{array}$ & $\begin{array}{l}\text { Duration of } \\
\text { follow-up } \\
\text { (years) }\end{array}$ & $\begin{array}{l}\text { No. patients } \\
\text { with long-term } \\
\text { follow-up }\end{array}$ & $\begin{array}{l}\text { Timing of } \\
\text { follow-up } \\
\text { evaluation }\end{array}$ & $\begin{array}{l}\text { Revisions } \\
\text { Repeated } \\
\text { TIF/Sur- } \\
\text { gery No. } \\
\text { (\%) }\end{array}$ \\
\hline $\begin{array}{l}\text { Witteman, } \\
2012 \text { [12] }\end{array}$ & $\begin{array}{l}\text { EsophyX } \\
\text { TIF } 1.0\end{array}$ & 100 & $\begin{array}{l}65 \\
(35-142)\end{array}$ & $2(5.3)$ & 3 & 19 & Every year & $14(37)$ \\
\hline $\begin{array}{l}\text { Muls, } 2013 \\
\text { [11] }\end{array}$ & $\begin{array}{l}\text { EsophyX } \\
\text { TIF } 1.0\end{array}$ & 100 & NR & 0 & 3 & 54 & Every year & $12(13.9)$ \\
\hline $\begin{array}{l}\text { Roy-Shapira, } \\
2015 \text { [13] }\end{array}$ & MUSE & 86.7 & NR & 0 & 4 & 13 & Every year & 0 \\
\hline $\begin{array}{l}\text { Kim HJ, } 2016 \\
{[14]}\end{array}$ & MUSE & 100 & NR & $1(1.6)$ & 4 & 64 & Every year & 0 \\
\hline $\begin{array}{l}\text { Stefanidis, } \\
2017 \text { [16] }\end{array}$ & $\begin{array}{l}\text { EsophyX } \\
\text { TIF } 2.0\end{array}$ & 97.8 & $\begin{array}{l}60 \\
(45-100)\end{array}$ & $2(4.4 \%)$ & 5 & 44 & Every year & 0 \\
\hline $\begin{array}{l}\text { Trad KS, } \\
2018 \text { [15] }\end{array}$ & $\begin{array}{l}\text { EsophyX } \\
\text { TIF } 2.0\end{array}$ & 100 & $\begin{array}{l}49 \\
(21-119)\end{array}$ & 0 & 5 & 44 & Every year & $3(4.8)$ \\
\hline $\begin{array}{l}\text { Chimukangara } \\
\text { M, 2019 [18] }\end{array}$ & $\begin{array}{l}\text { Esophy X } \\
\text { TIF } 2.0\end{array}$ & 100 & NR & NR & 8 & 57 & $\begin{array}{l}1 \text { - and } \\
8 \text {-year }\end{array}$ & $12(21.1)$ \\
\hline $\begin{array}{l}\text { Testoni PA, } \\
2019 \text { [17] }\end{array}$ & $\begin{array}{l}\text { EsophyX } \\
\text { TIF } 2.0\end{array}$ & 98 & $69 \pm 19$ & $2(4.0)$ & 10 & 12 & $\begin{array}{l}\text { 1-, 2-, 3-, 5-, } \\
7-\text { and } 10- \\
\text { year }\end{array}$ & $7(14)$ \\
\hline
\end{tabular}




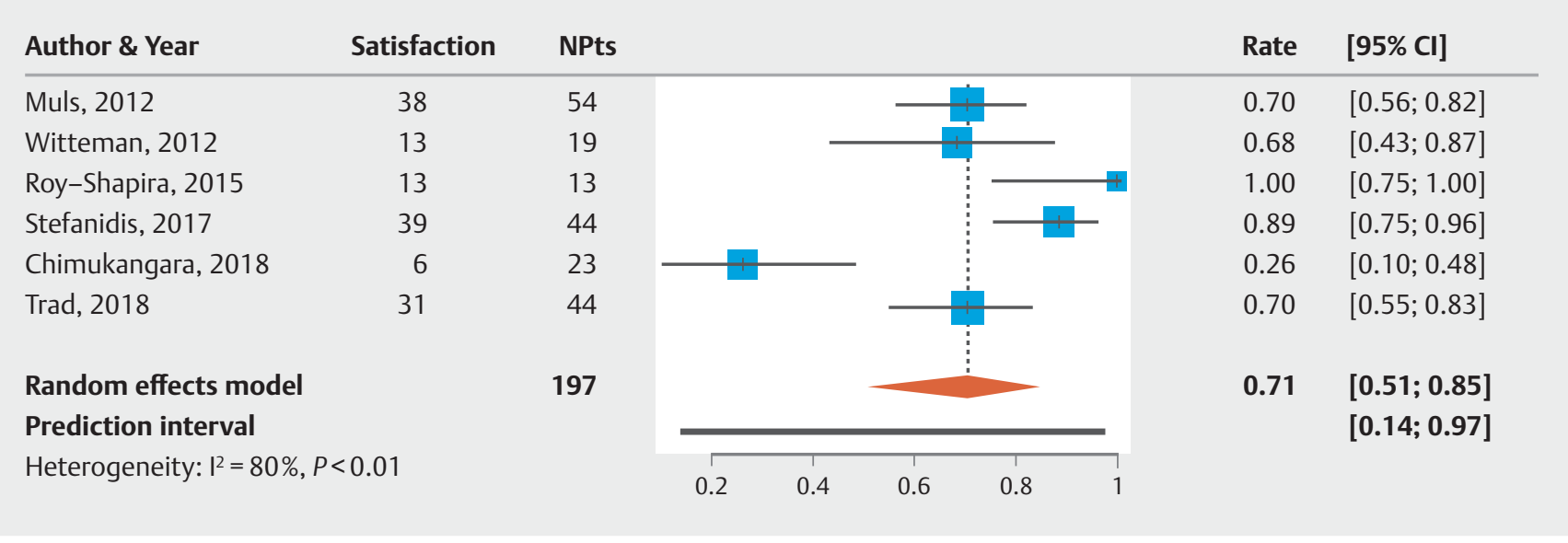

- Fig. 2 Meta-analysis of patient-reported satisfaction after TIF.

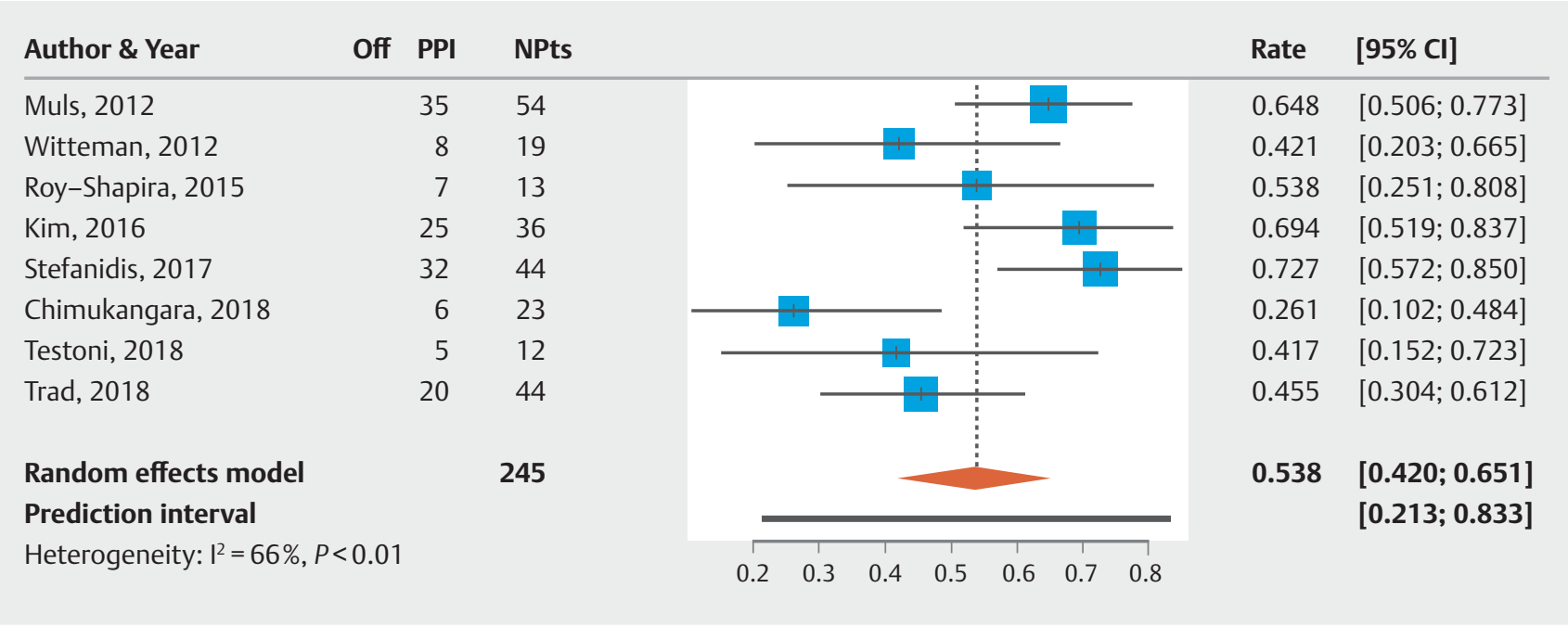

- Fig. 3 Meta-analysis of patients who were completely free of PPIs.

[18] (pooled rate estimate, 76.0\% (95\% Cl:65.0-84.0\%); $\mathrm{I}^{2}=$ $44,5 \%$, Egger test: $z=1.26, P=0.200)$. The median rates of patients who were satisfied with TIF after 3 years $[11,12], 4$ to 5 years $[13,15,16])$, and 8 years $[18]$ were $74.0 \%, 86.2 \%$, and $78 \%$, respectively.

\section{Patients off PPI or occasionally on PPI after TIF}

The overall pooled rate of patients completely off PPI was $53.8 \%$ (95\% Cl: $42.0 \%-65.1 \%, \mathrm{I}^{2}=66.2 \%$ ) with no publication bias (Egger test: $z=-0.1578, P=0.8746)$. The heterogeneity improved after the exclusion of one study [12] (pooled rate estimate: 59.0\%; 95\% Cl: 52.2-65.5; $\mathrm{I}^{2}=52.6 \%$ ) ( Fig.3). The pooled percentage of patients who were either completely off or took PPIs occasionally was $75.8 \%\left(95 \% \mathrm{Cl}\right.$ : 67.6-82.6; $\mathrm{I}^{2}=$ $22.1 \% ; P=0.267,>$ Fig. 4 ). Such rates at 3,4 to 5 , and 8 to 10 years were $53.5 \% / 73.8 \%, 57.5 \% / 76.4 \%$, and $34.4 \% / 91.7 \%$, respectively.

The pooled rates of patients completely off PPI and who were either completely off or only took PPIs occasionally were
65.3\% and 54\%, after Esophyx and MUSE, respectively, and this difference was not statistically significant $(P=0.2)$

\section{GERD-HRQL score at baseline and after TIF}

The pooled estimated mean GERD-HRQL scores off PPI before TIF and after TIF at a mean follow-up of 5.3 years were 26.1 (95\% Cl: 21.5-30.7) and 5.9 (95\% Cl: 0.35.1-11.4), indicating that post TIF mean-HRQL scores significantly improved $(P<$ $0.001)$. However, based on the $Q$-statistic $(P<0.05)$, there appeared to be statistically significant heterogeneity between score estimates reported by the studies. $>$ Table 3 summarizes GERD-HRQL scores at 3-, 4- to 5-, and 8- to 10-year follow-up.

In the four studies in which GERD-HLQR before TIF was calculated also for patients on PPI therapy, the scores off PPIs after TIF were significantly better compared with those on PPIs before TIF, at 3, 5, and 10 years. Overall, GERD-HLQR scores after TIF improved by four-fifths and remained stable up to 4 to 5 years, while at 10-year follow-up, they appeared improved by two-thirds with a $57.1 \%$ worsening of GERD-related symptoms. 


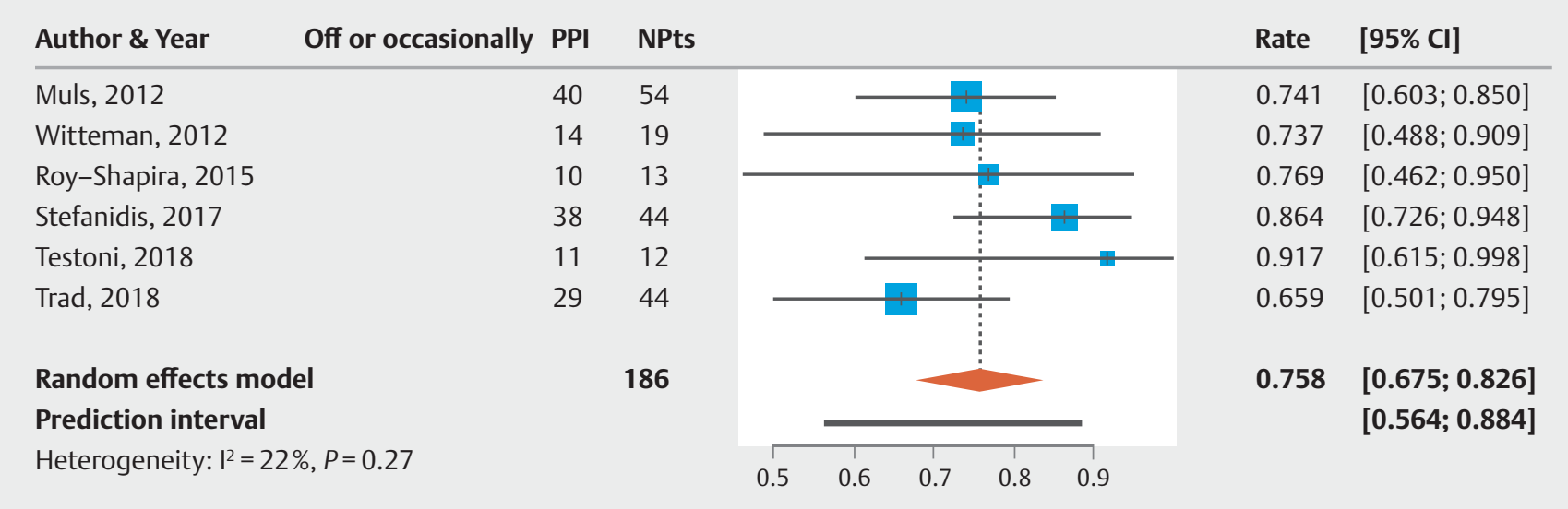

Fig. 4 Meta-analysis of patients who were completely free of PPIs or took them occasionally.

- Table 3 Patient satisfaction, GERD-HRQL scores, and PPI consumption at 3-, 4- to 5-, and 8- to 10-year follow-up.

\begin{tabular}{|c|c|c|c|c|c|c|c|c|c|}
\hline \multirow[t]{2}{*}{$\begin{array}{l}\text { Author, publi- } \\
\text { cation year }\end{array}$} & \multirow[t]{2}{*}{$\begin{array}{l}\text { Long-term } \\
\text { follow-up, } \\
\text { years }\end{array}$} & \multicolumn{2}{|c|}{$\begin{array}{l}\text { Patient satisfaction, } \\
\text { no. }(\%)\end{array}$} & \multicolumn{2}{|c|}{$\begin{array}{l}\text { GERD-HRQL score, median } \\
\text { (range) or mean } \pm S D\end{array}$} & \multicolumn{2}{|c|}{$\begin{array}{l}\text { Patients off-PPI no. } \\
\text { (\%) }\end{array}$} & \multicolumn{2}{|c|}{$\begin{array}{l}\text { Patients off-PPI| } \\
\text { occasionally on PPI, } \\
\text { N. (\%) }\end{array}$} \\
\hline & & Pre-TIF & Post-TIF & Pre-TIF & Post-TIF & Pre-TIF & Post-TIF & Pre-TIF & Post-TIF \\
\hline $\begin{array}{l}\text { Witteman, } 2012 \\
\text { [12] }\end{array}$ & 3 & 0 & $27(70)$ & $33(7-69)$ & $5(0-29)$ & $3(15.8)$ & $8(42.1)$ & NR & 11 (57.9) \\
\hline Muls, 2013 [11] & 3 & $3(6)$ & $38(70)$ & $25(13-38)$ & $4(0-32)$ & NR & NR & NR & NR \\
\hline $\begin{array}{l}\text { Roy-Shapira, } \\
2015 \text { [13] }\end{array}$ & 4 & 0 & $13(100)$ & $24.2 \pm 6.9$ & $5(1-15)$ & 0 & 10 (76.9) & 0 & $13(100)$ \\
\hline $\begin{array}{l}\text { Kim HJ, } 2016 \\
{[14]}\end{array}$ & 4 & NR & NR & $66.1 \pm 33.2$ & $12.8 \pm 19.4$ & NR & $25(69.4)$ & NR & NR \\
\hline $\begin{array}{l}\text { Stefanidis, } 2017 \\
{[16]}\end{array}$ & 5 & 0 & $32(72.7)$ & $27(2-45)$ & $4(0-26)$ & 0 & $32(72.7)$ & 0 & $38(86.4)$ \\
\hline $\begin{array}{l}\text { Trad KS, } 2018 \\
\text { [15] }\end{array}$ & 5 & $1(2.3)$ & $33(75)$ & 26.4 & 6.8 & 0 & $20(45.5)$ & 0 & 29 \\
\hline $\begin{array}{l}\text { Chimukangara } \\
\text { M, 2019 [18] }\end{array}$ & 8 & 0 & $18(78.3)$ & $24(15-28)$ & $10(6-14)$ & 0 & $6(26.1)$ & NR & NR \\
\hline $\begin{array}{l}\text { Testoni PA, } \\
2019 \text { [17] }\end{array}$ & 10 & NR & NR & $46 \pm 19$ & $9.5 \pm 6.1$ & 0 & $5(41.7)$ & 0 & 11 (91.7) \\
\hline
\end{tabular}

\section{Normalization of heartburn and regurgitation score after TIF}

Data for heartburn normalization were available for 133 patients from four studies $[11,12,15,16]$. Meta-analysis of these trials yielded an overall pooled rate of heartburn normalization of $73.0 \%$ (95\% Cl: $0.62-0.82$ ). Only three trials (80 patients) reported data on regurgitation score after TIF $[12,15,16]$. Combining data from these three trials, the pooled rate of resolution of regurgitation was $86 \%$ ( $95 \% \mathrm{Cl}$ : 75.0-91.0\%). One study reported heartburn and regurgitation scores pre- and post-TIF, instead of normalization, with significant improvement for both (heartburn score: $4.2 \pm 3$ vs $18 \pm 9$ pre-TIF; regurgitation score $3.2 \pm 4.4$ vs $17 \pm 9$ pre-TIF; $P<0.01$ ) [17].

The median pooled rates of patients with normalized heartburn and regurgitation scores after TIF 3 and 4 to 5 years were r68.6\%/79\% and $86.2 \% / 87.1 \%$, respectively.

\section{Discussion}

According to our meta-analysis, TIF resulted in long-term patient satisfaction rates of $74 \%$ to $86 \%$, with interruption/reduction of PPI in about $75 \%$ of cases at 3 and 4 to 5 years, and with a significant and persistent improvement in GERD-related symp- 
toms and quality of life in four-fifths and two-thirds of patients at 4 to 5 and 10 years, respectively.

These results are clinically relevant because they show that the satisfactory outcomes reported after TIF in the short term are maintained even in the long term, arguing in favor of TIF as an effective alternative to surgery in selected patients. Our data confirm and strengthen over the long term the results of two previous pooled analyses of short-term [1,2] reporting a short-term success rate of $99 \%$ and a low rate $(2 \%)$ of serious AEs.Overall, up to 10 years after TIF, about two-thirds of patients were satisfied, compared with before TIF, and the satisfaction rate appeared to be maintained over time.

These long-term TIF outcomes can be compared with those reported after laparoscopic surgical fundoplication. In detail, after TIF, pooled PPI interruption or reduction was observed in $53.8 \%$ and $75.8 \%$ of patients, respectively, versus a 5 -year post anti-reflux-surgery use of PPI nationwide survey showing that $57.5 \%$ and $29.5 \%$ of patients still took PPIs or were daily PPI-dependent [19]. The symptom normalization found by our study of $73 \%$ is higher than reported by a Cochrane meta-analysis on long-term results of Nissen fundoplication, showing recurrence or persistence of heartburn and reflux symptoms in $41.2 \%$ and $24.6 \%$ of cases, respectively, with persistent side effects in $14 \%$ up to $23 \%$ of cases [20].

There are very few reports on 10-year outcomes after surgical fundoplication, but again, results are substantially comparable with our TIF findings [20, 21-23].

This analysis has limitations, partly due to the nature of included studies. First, the long-term follow-up in most included studies (3 to 10 years) was rarely carried out with a complete clinical assessment (i.e. endoscopic and/or functional evaluations) in a small number of patients; however, studies evaluating long-term outcomes (5 to 10 years) after surgical fundoplication also harbor the same limitations (usually assessing only clinical outcomes) permitting nonetheless a trustworthy comparison. Furthermore, the symptomatic curve over a such long period suggests that the results would not change much even with a larger number of fully-assessed patients. Second, a high heterogeneity across studies for patient reported overall satisfaction after TIF was found. However, this result must be analyzed next to the substantial reduction in overall PPI use, which yielded a much lower heterogeneity, as well as the solid reduction in GERD QoL scores that was maintained over time, which are both more objective parameters for evaluating procedure outcomes.

\section{Conclusion}

In conclusion, this meta-analysis showed that pooled long-term post-TIF data seem sufficient to confirm that TIF appears to offer a therapeutic option as effective as surgery in the long term and safe for selected symptomatic patients with GERD, with a Hill grade I or II gastroesophageal valve or a hiatal hernia no longer than $2.5 \mathrm{~cm}$, who refuse life-long medical therapy or surgery, are intolerant to PPIs, or are at risk of persistent postsurgical side effects.

\section{Competing interests}

The authors declare that they have no conflict of interest.

\section{References}

[1] Huang X, Chen S, Zhao H et al. Efficacy of transoral incisionless fundoplication (TIF) for the treatment of GERD: a systematic review with meta-analysis. Surg Endosc 2017; 31: 1032-1044

[2] McCarty TR, Itidiare M, Njei B et al. Efficacy of transoral incisionless fundoplication for refractory gastroesophageal reflux disease: a systematic review and meta-analysis. Endoscopy 2018; 50: 708-725

[3] Richter JE, Kumar A, Lipka S et al. Efficacy of laparoscopic nissen fundoplication vs transoral incisionless fundoplication or proton pump inhibitors in patients with gastroesophageal reflux disease: a systematic review and network meta-analysis. Gastroenterology 2018; 154: $1298-1308$

[4] Liberati A, Altman DG, Tetzlaff J et al. The PRISMA statement for reporting systematic reviews and meta-analyses of studies that evaluate health care interventions: explanation and elaboration. Ann Intern Med 2009; 151: W65-W94

[5] Moga C, Guo B, Schopflocher D et al. Development of a quality appraisal tool for case series studies using a modified Delphi technique. Inst Health Econ; 2012: Available at: https://www.ihe.ca/advancedsearch/development-of-a-quality-appraisal-tool-for-case-series-studies-using-a-modified-delphi-technique

[6] Jadad AR, Moore RA, Carroll D et al. Assessing the quality of reports of randomized clinical trials: is blinding necessary? Control Clin Trials 1996; 17: 1-12

[7] Higgins JP, Thompson SG, Deeks JJ et al. Measuring inconsistency in meta-analyses. BMJ 2003; 327: 557-560

[8] Viechtbauer W, Cheung MW. Outlier and influence diagnostics for meta-analysis. Res Synth Methods 2010; 1: 112-125

[9] Egger M, Davey Smith G, Schneider M et al. Bias in meta-analyses detected by a simple graphical test. BMJ 1997; 315: 629-634

[10] Viechtbauer W. Conducting meta-analyses in R with the metaphor package. J Statist Software 2010; 36: 1-48

[11] Muls V, Eckardt AJ, Marchese M et al. Three-year results of a multicenter prospective study of transoral incisionless fundoplication. Surgical Innovation 2013; 20: 321-330

[12] Witteman PBL, Strijkers R, de Vries E et al. Transoral incisionless fundoplication for treatment of gastroesophageal reflux diseases in clinical practice. Surg Endosc 2012; 26: 3307-3315

[13] Roy-Shapira A, Bapaye A, Date $S$ et al. Trans-oral anterior fundoplication: 5-year follow-up of pilot study. Surg Endosc 2015; 29: 37173721

[14] Kim HJ, Kwon Cl, Kessler WR et al. Long-term follow-up results of endoscopic treatment of gastroesophageal reflux disease with the MUSE ${ }^{T M}$ endoscopic stapling device. Surg Endosc 2016; 30: 34023408

[15] Trad KS, Barnes WE, Prevou ER et al. The TEMPO trial at 5 years: transoral fundoplication (TIF 2.0) is safe, durable, and cost-effective. Surg Innov 2018; 25: 149-157

[16] Stefanidis G, Viazis N, Kotsikoros N et al. Long-term benefit of transoral incisionless fundoplication using the Esophyx device for the management of gastroesophageal reflux disease responsive to medical therapy. Dis Esophagus 2017; 30: 1-8

[17] Testoni PA, Testoni S, Distefano G et al. Transoral incisionless fundoplication with EsophyX for gastroesophageal reflux disease: clinical efficacy is maintained up to 10 years. Endosc Int Open 2019; 7: E647E654 
[18] Chimukangara M, Jalilvand AD, Melvin WS et al. Long-term reported outcomes of transoral incisionless fundoplication: an 8-year cohort study. Surg Endosc 2019; 33: 1304-1309

[19] Loedrup A, Pottegard A, Hallas J et al. Use of proton pump inhibitors after antireflux surgery. A nationwide register-based follow-up study. Gut 2014; 63: 1544-1549

[20] Garg SK, Gurusamy KS. Laparoscopic fundoplication surgery versus medical management for gastro-oesophageal reflux disease (GORD) in adults. Cochrane Database Syst Rev 2015; 11: CD003243
[21] Lundell L, Bell M, Ruth M. Systematic review: laparoscopic fundoplication for gastro-esophageal reflux disease in partial responders to proton pump inhibitors. World J Gastroenterol 2014; 20: 804-813

[22] Kelly JJ, Watson DI, Chin KF et al. Laparoscopic Nissen fundoplication: clinical outcomes at 10 years. J Am Coll Surg 2007; 205: 570-575

[23] Gunter RL, Shada AL, Funk LM et al. Long-term quality of life outcomes following Nissen versus Toupet fundoplication in patients with gastroesophageal reflux disease. J Laparoendosc Adv Surg Tech A 2017; 27: 931-936 